\title{
Properties of crackers with buckwheat sourdough
}

\author{
Amel Selimovića ${ }^{a}$ Dijana Miličevića, Amra Selimovića \\ Sanja Oručević Žuljevićb, Amela Jašića ${ }^{\mathrm{a}}$, Amila Vranac ${ }^{\mathrm{b}}$ \\ ${ }^{a}$ Faculty of Technology, University of Tuzla, Univerzitetska 8, 75000 Tuzla, Bosnia and Herzegovina \\ ${ }^{b}$ Faculty of Agricultural and Food Science, University of Sarajevo, \\ Zmaja od Bosne 8, 71000 Sarajevo, Bosnia and Herzegovina \\ amel.selimovic@untz.ba
}

\begin{abstract}
Effects of additions of buckwheat flour and sourdough on the total phenols content, antioxidant activity, and sensory properties of crackers were examined. Different mixtures of wheat flour with addition of buckwheat flour and sourdough were used for the prepartion of crackers. Two types of lactic acid bacteria (Lactobacillus plantarum and Lactobacillus brevis) were used for the preparation of buckwheat sourdough. Properties of crackers made with addition of buckwheat flour and sourdough were analysed in comparison to control crackers made only with wheat flour.

Significant increase of total phenols in comparison to wheat flour dough $(0.73 \mathrm{mg}$ gallic acid equivalent (GA)/g of dry basis (d.b.)) was accomplished by adding buckwheat flour (1.12 mg GA/g d.b.) and sourdough (1.77 and $1.79 \mathrm{mg} \mathrm{GA} / \mathrm{g}$ d.b.) regardless of the type of lactic acid bacteries used. All samples showed the decrease in total phenol content during baking process. Crackers with sourdough had higher antioxidant

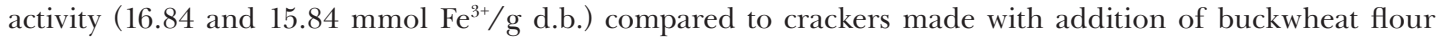
(10.42 mmol Fe $\mathrm{Fe}^{3+} / \mathrm{g}$ d.b.) and control sample $\left(7.76 \mathrm{mmol} \mathrm{Fe} \mathrm{s}^{3+} / \mathrm{g}\right.$ d.b.). The result of sensory analysis showed positive influence of sourdough on taste and texture of crackers and insignificant differences in odour and appearance of tested samples. Also, the chewiness of crackers made with the addition of buckwheat flour and sourdough was improved compared to control crackers made from wheat flour.
\end{abstract}

Key words: buckwheat, sourdough, crackers, total phenols, FRAP, sensory analyses

\section{Introduction}

Bakery products with added sourdough are being reintroduced to industrial production in recent years. It is a result of consumer demand for more natural and tastier food and increasing demand for products with improved nutritional value and potential preventive health benefits. Use of sourdough in bread production is one of the oldest biotechnological processes. Sourdough is made by fermenting dough in the environment of naturally present flour micro-flora (spontaneous fermentation) or by adding starter culture comprised of one or more selected types of fermented lactic acid bacteria (LAB) and yeast. The use of sourdough increases the durability of the product and affects the flavour. The main product of LAB fermentation is lactic acid which increases dough acidity, prevents reproduction of unwanted microorganisms, increases shelf-life of product and affects flavour (Armero and Collar, 1996). During fermentation of sourdough chemical composition changes as well as microbial status, behaviour, viscosity and dough thickness, so that the use of sourdough changes technological properties of dough, structure, nutritional value and product flavour (Meuser and Zense, 1993; Wehrle and Arendt, 1998). Change in $\mathrm{pH}$ value, following LAB metabolite build-up, affects enzyme activity in sour- dough. Quick drop in $\mathrm{pH}$ leads to activation of LAB proteolytic enzymes and gluten degradation (Thiele et al., 2002). Proteolysis during fermentation stimulates microbial growth, while released amino acids directly or precursory contribute to development of flavour (Clarke and Farrell, 2000). Low pH values reduces enzyme activity of flour amylase and hydrolysis of starch, which as a consequence influences shelf-life and product quality (Wehrle et al., 1997; Clarke et al., 2002; Angioloni et al., 2006). Research has shown that during lactic acid dough fermentation enzyme phytase is activated and lowers the amount of phytic acid, and then increases biological availability of minerals (Katina et al., 2005; Di Cagno et al., 2008). Even with little available data, previous research have shown that fermentation can affect the amount of easily extractable phenol compounds and anti-oxidative activity of flour. Also, by fermenting sourdough you can increase or decrease the content of certain bioactive components, that is, by selecting sourdough starter cultures and fermentation conditions (temperature, time) both composition and amount of certain bioactive compounds can be modified and influence the anti-oxidative activity as well (Liukkonen et al., 2003; Katina et al., 2005; Katina et al., 2007; Michalska et al., 2007; Banu et al., 2010; Đorđević et al., 2010). Crackers are categorized as finer bakery products and it is typical for 
them that when preparing dough, gluten net need to be but slightly developed, so the dough could be cohesive but no too elastic (Schober et al., 2003). Also, crackers can be defined as cookies, which are more or less unsweetened, salty, crunchy and with low fat content. Cereal products, especially those in bakery industry, are one of the most representatives in consumer diet, and improving the assortment of these products regarding functionality might represent a contribution to the use food ameliorating general health of population (Sedej, 2011). To the best of our knowledge there is no available published data reporting on cracker formulation containing buckwheat sourdough fermented with Lactobacillus plantarum and Lactobacillus brevis. Recent studies are mainly oriented to enhancing nutritional value and functional properties of crackers through incorporation of non-traditional raw materials such as buckwheat flour (Sedej, 2011; Sedej et al., 2011), pumpkin pulp, unripe banana pulp, unripe mango pulp and peel (Noor Aziah and Komathi, 2009) or pumpkin pomace powder (Kuchtová et al., 2016).

The aim of this paper was to examine the influence of adding buckwheat sourdough on sensory and anti-oxidative properties of crackers in comparison to wheat flour crackers as a control sample.

\section{Material and methods}

\section{Materials}

The ingredients used in the crackers production were commercial wholegrain buckwheat flour, wheat flour, corn flour, baking powder, salt, pow- dered sugar, vegetable fat and flaxseed. All ingredients were purchased from the local market. Freeze dried starter culture of lactic acid bacteria (Clerici Sacco, Italy), Lactobacillus plantarum (Lyoflora B2) and Lactobacillus brevis (Lyoflora B4) are used as starter in sourdough fermentation.

\section{Preparation of sourdoughs with Lactobacillus plantarum and Lactobacillus brevis}

Sourdough was prepared from buckwheat flour $(200 \mathrm{~g})$, sterilized water $\left(200 \mathrm{~mL}, 30{ }^{\circ} \mathrm{C}\right)$ and freeze dried starter culture ((Lactobacillus plantarum (LP) and Lactobacillus brevis (LB)). The latest was added to give $10^{8}$ colony-forming units $(\mathrm{cfu})$ per gram of sourdough. First, starter culture was dissolved in water and after 5 minutes added to flour. This was mixed by hand with spoon and incubated for $20 \mathrm{~h}$ at $30^{\circ} \mathrm{C}$ (Hansen and Hansen, 1994).

\section{Crackers production procedure}

Ingredients for crackers dough were added in the amounts shown in the Table 1. Flaxseeds and salt were soaked in water for $2 \mathrm{~h}$, while corn flour was steamed with hot water $\left(85^{\circ} \mathrm{C}\right)$ and cooled to the room temperature. Previously fermented sourdough was weighed to amounts given in the Table 1. Next, all ingredients were mixed with a kitchen blender. Dough was rolled into polyethylene bags and left at room temperature for one hour. Then, dough was formed by hand to a thickness of about $5 \mathrm{~mm}$ and cut into rectangles with dimensions $50 \times 60 \mathrm{~mm}$. Baking was conducted at $200{ }^{\circ} \mathrm{C}$ for 20 minutes (Sedej, 2011). After 30 minutes of cool-

Tab. 1. Formulation of the crackers.

\begin{tabular}{|c|c|c|c|c|}
\hline \multirow{2}{*}{ Ingredients (g) } & \multicolumn{4}{|c|}{ Crackers } \\
\hline & $\mathrm{W}$ & $\mathrm{W}+\mathrm{BF}$ & W+BSD_LP & W+BSD_LB \\
\hline Wheat flour & 70 & 50 & 50 & 50 \\
\hline Buckwheat flour & 0 & 20 & 0 & 0 \\
\hline $\begin{array}{l}\text { Buckwheat sourdough fermented } \\
\text { with L. plantarum (LP) }\end{array}$ & 0 & 0 & $40 *$ & 0 \\
\hline $\begin{array}{l}\text { Buckwheat sourdough fermented } \\
\text { with L. brevis (LB)* }\end{array}$ & 0 & 0 & 0 & $40 *$ \\
\hline Corn flour & 30 & 30 & 30 & 30 \\
\hline Baking powder & 1 & 1 & 1 & 1 \\
\hline Powdered sugar & 2.5 & 2.5 & 2.5 & 2.5 \\
\hline Salt & 3.5 & 3.5 & 3.5 & 3.5 \\
\hline Vegetable fat & 30 & 30 & 30 & 30 \\
\hline Flaxseed & 10 & 10 & 10 & 10 \\
\hline Water & 50 & 50 & 30 & 30 \\
\hline
\end{tabular}

${ }^{*} 40 \mathrm{~g}$ sourdough $=20 \mathrm{~g}$ flour $+20 \mathrm{~mL}$ water.

W - Wheat crackers; W + BF - Wheat crackers with buckwheat flour; W + BSD_LP - Wheat crackers with buckwheat sourdough fermented with $L$. plantarum (LP); W + BSD_LB - Wheat crackers with buckwheat sourdough fermented with $L$. brevis (LB). 
ing at room temperature, crackers were packed into aluminium foil and kept at room temperature for further examinations.

\section{Analyses of pH and total titratable acidity (TTA)}

The $\mathrm{pH}$ value of sourdough, fermented dough or cracker, was measured from an aliquot of $10 \mathrm{~g}$ of sample blended with $100 \mathrm{~mL}$ of acetone/water (5:95, v/v) under constant agitation. TTA was determined by titrating this suspension against $0.1 \mathrm{M}$ $\mathrm{NaOH}$ to a final value of $\mathrm{pH}$ 8.5. The results were expressed as the volume (millilitre) of $0.1 \mathrm{M} \mathrm{NaOH}$ needed for titrating $10 \mathrm{~g}$ of sourdough, fermented dough or cracker (Sanz Penella et al., 2012).

\section{Extraction of total phenols from dough and crackers} In all samples of dough and crackers, total phenols were extracted with water as described in the literature (Selimović, 2014). First, crackers were grinding in a kitchen electric mill to a small granulation which is easy to homogenize. Samples (2 g) of the dough and crackers were taken for extraction and diluted in $20 \mathrm{~mL}$ distilled water. The content was mixed from time to time for 30 minutes at room temperature $\left(20^{\circ} \mathrm{C}\right)$, and then filtered through the filter paper. The extract obtained by this procedure was used for determination of antioxidant activity and total phenols content.

\section{Determination of total phenols $(T P)$ content}

Total phenols (TP) in water extracts of doughs and crackers were determined with Folin-Ciocalteu reagent using gallic acid as a standard (Singleton et al., 1999). The extract $(200 \mu \mathrm{L})$ was mixed with $2 \mathrm{~mL}$ of Folin-Ciocalteu reagent (previously diluted 10 times with distilled water). After 5 minutes, $1.8 \mathrm{~mL} \mathrm{so-}$ dium bicarbonate solution $(7.5 \% \mathrm{w} / \mathrm{v})$ was added to the mixture and after incubation for $120 \mathrm{~min}$ at room temperature, the absorbance was measured at $765 \mathrm{~nm}$ using a UV/VIS spectrophotometer (UV mini 1240, Shimadzu). The concentration of total phenols compounds in extracts was determined as gallic acid equivalent (GA) using an equation $\left(\mathrm{Y}=5.266 \mathrm{X}-0.0047 ; \mathrm{R}^{2}=0.9992\right)$ obtained from a calibration curve. Results are expressed as mg GA/g d.m. sample. All measurements were repeated three times and expressed as the mean value.

\section{Determination of total antioxidant activity}

The antioxidant activity of water extracts of doughs and crackers was determined by FRAP (Ferric Reducing Antioxidant Power) method (Benzie and Strain, 1996). FRAP reagent was prepared by mixing TPTZ (2,4,6-tripyridyl-s-triazine) solution (10 mM TPTZ solution was prepared in $10 \mathrm{~mL}$ of $40 \mathrm{mM} \mathrm{HCl}), 20 \mathrm{mM} \mathrm{FeCl} l_{3} \cdot 6 \mathrm{H}_{2} \mathrm{O}$ and acetate buffer $(0.3 \mathrm{~mol} / \mathrm{L}, \mathrm{pH} 3.6)$ in the ratio $1: 1: 10$. All solutions were used on the day of preparation. FRAP reagent was prepared and kept at $37^{\circ} \mathrm{C}$. A volume of $200 \mu \mathrm{L}$ extract was mixed with $1.8 \mathrm{~mL}$ of FRAP reagent and the absorbance of the reaction mixture was measured at $593 \mathrm{~nm}$ (UV mini 1240, Shimadzu) after incubation at $37{ }^{\circ} \mathrm{C}$ for $10 \mathrm{~min}$. The antioxidant activity was determined as $\mathrm{mmol} \mathrm{Fe} \mathrm{F}^{3+} / \mathrm{g}$ d.m. of sample using an equation $\left(\mathrm{Y}=0.5371 \mathrm{X}+0.0703 ; \mathrm{R}^{2}=0.9949\right)$ obtained from a calibration curve. Calibration curve was prepared using different concentrations $(50-1000 \mu \mathrm{mol} / \mathrm{L})$ of $\mathrm{FeSO}_{4} \cdot 7 \mathrm{H}_{2} \mathrm{O}$ and absorbance were measured as above. All measurements were repeated three times and expressed as the mean value.

\section{Sensory analyses}

Sensory analyses of the crackers, which included evaluation of the representative properties of crackers done by the points-based method ( $1-5$ points) as described in details in the literature (Sedej, 2011; Sedej et al. 2011) with some modification. Sensory evaluation was conducted $24 \mathrm{~h}$ after baking by seven untrained panelists (students of the Faculty of Technology, University of Tuzla, 6 females and 1 male, at the age of 21 to 24). Panelists were required to evaluate the appearance (shape, uniformity, surface), texture (structure, break and firmness), chewiness, odour and taste of the crackers. For each individual sensory property assigned points are multiplied with the following factors of significance (FS): FS $=1.0$ for appearance (shape, uniformity, surface); FS = 1.2 for structure, break and firmness; FS = 1.0 for chewiness; FS = 0.6 for odour and $\mathrm{FS}=1.2$ for taste. By applying significance factors, quantitative aspect as a weighted mean value for certain properties is produced. Quality categories of crackers are determined based on value range so that crackers with $<2.5$ are considered of unsatisfactory quality; those from 2.5 to 3.5 good, 3.5 to 4.5 very good and from 4.5 to 5 of excellent sensory quality (Sedej, 2011).

\section{Statistical analyses}

One-way analysis of variance (ANOVA) and multiple comparisons (Duncan's post-hoc test) were used to evaluate the significant difference of the data at $\mathrm{p}<0.05$. Data were analysed using the software package SPSS V.15.

\section{Results and discussion}

Change in $\mathrm{pH}$ value and total titratable acidity (TTA) during fermentation of buckwheat sourdough are shown in the Fig. 1. Measurements were done after 6 , 12 and $24 \mathrm{~h}$. During first $6 \mathrm{~h}$ of sourdough fermenta- 
tion, regardless of starter culture used (L. plantarum or L. brevis), changes in pH and TTA were minimal. After 12 hours, a significant drop in $\mathrm{pH}$ from 6.2 to 5.14 (sample with L. plantarum) occurred. In sample with $L$. brevis, the change from 6.2 to 4.92 was observed. Concomitantly, TTA also significantly increased (around 2.5 times). The $\mathrm{pH}$ value after $24 \mathrm{~h}$ of fermentation was about 3.9. Thus, these results show that both starter cultures used manifest similar trends in fermentation, that is, a drop in $\mathrm{pH}$ value. Because of accumulation of organic acids (lactic, acetic acid) as products of bacterial metabolism during the lactic acid fermentation, there is an increase in total acidity. Results have shown that TTA increased more than 5 times. In sourdough with $L$. plantarum it was $16.1 \mathrm{~mL}$, while samples with $L$. brevis were more acidic $(17.8 \mathrm{~mL})$. Although the starting values of TTA were the same, difference in total acidity is a possible consequence of different metabolisms in these two bacteria. L. brevis creates both lactic and acetic acid as the metabolic products, which explains higher acidity in dough fermenting with addition of L. brevis, than of L. plantarum. The higher acidity can be a consequence of accumulation of total organic acids in higher concentrations.

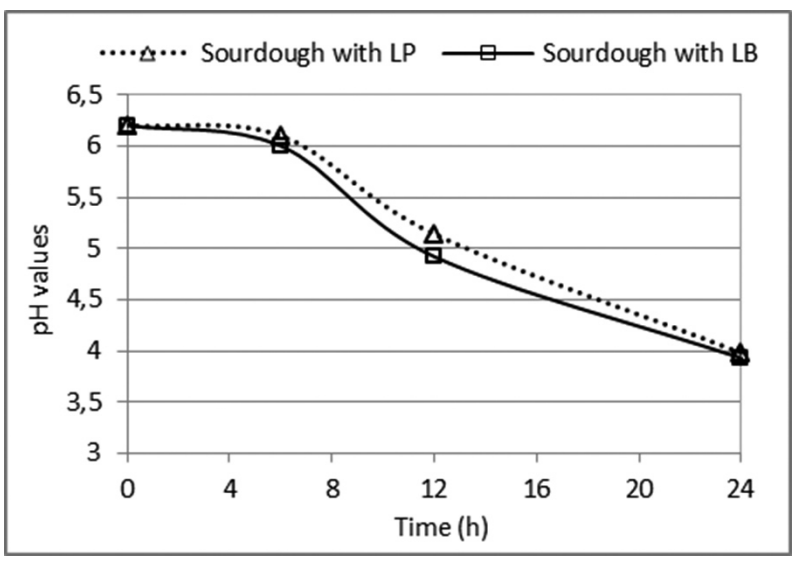

Table 2 shows the dough $\mathrm{pH}$ and TTA measurement results in crackers production. As expected, adding sourdough (regardless of used starter culture) significantly ( $\mathrm{p}<0.05$ ) lowered dough $\mathrm{pH}$ value and increased its TTA in comparison to control sample (W). Adding buckwheat flour did not significantly influence the change of dough $\mathrm{pH}$ and TTA. Crackers with sourdough had lower $\mathrm{pH}$ in comparison with control sample (W) and buckwheat flour sample $(\mathrm{W}+\mathrm{BF})$.

Also, comparing dough samples $\mathrm{pH}$ and TTA with crackers samples it can be seen that baking process did not significantly influence the change in pH and TTA (table 2). Both control sample and buckwheat crackers had significantly $(\mathrm{p}<0.05)$ lower TTA in comparison with sourdough crackers. Crackers with buckwheat sourdough (W + BSD_LP and $\mathrm{W}+$ BSD_LB $)$ had greatest acidity $(6.4 \mathrm{~mL}$ and $6.5 \mathrm{~mL})$.

Buckwheat contains a many of bioactive components (phenol compounds, rutin and quercetin), due to which it shows significant antioxidative activity compared to wheat and other grains (Dietrych-Szostak and Oleszek, 1999; Kreft et al., 1999; Christa and Soral-Śmietana, 2008). The results (Fig. 2) show

Fig. 1. Values of the pH and TTA in buckwheat sourdough during fermentation (LP - Lactobacillus plantarum; LB - Lactobacillus brevis).

Tab. 2. Values of both pH and TTA of dough for crackers and crackers.

\begin{tabular}{ccccc|cccc}
\hline \multicolumn{9}{c}{ Samples } \\
\hline \multicolumn{3}{c}{ Dough for crackers } & \multicolumn{3}{c}{ Crackers } \\
\hline pH & W & W + BF & W + BSD_LP & W + BSD_LB & W & W + BF & W + BSD_LP & W + BSD_LB \\
TTA & $6.57^{\mathrm{a}}$ & $6.45^{\mathrm{a}}$ & $5.81^{\mathrm{b}}$ & $5.75^{\mathrm{b}}$ & $6.40^{\mathrm{a}}$ & $6.33^{\mathrm{a}}$ & $5.75^{\mathrm{b}}$ & $5.66^{\mathrm{b}}$ \\
\hline
\end{tabular}

"Results are presented as the mean value of the four replications.

**:Values in the same row marked with different letters are statistically significantly different $(\mathrm{p}<0.05)$.

W - Wheat crackers; W + BF - Wheat crackers with buckwheat flour; W + BSD_LP - Wheat crackers with buckwheat sourdough fermented with $L$. plantarum (LP); W + BSD_LB - Wheat crackers with buckwheat sourdough fermented with $L$. brevis (LB). 
that by substituting of part of wheat flour with buckwheat or sourdough can increase TP content in dough. Using buckwheat sourdough contributed to greater increase in TP content in relation to adding buckwheat. Sourdough samples W + BSD_LP $(1.77 \pm 0.03 \mathrm{mg}$ GA/g d.b.) and $\mathrm{W}+$ BSD_LB $(1.79 \pm 0.01 \mathrm{mg} \mathrm{GA} / \mathrm{g}$ d.b.), regardless of starter culture had about 2.5 times greater TP content in comparison to wheat dough $(0.73 \pm 0.01 \mathrm{mg} \mathrm{GA} / \mathrm{g}$ d.b.) and 1.5 times greater $\mathrm{TP}$ content in relation to adding $20 \%$ of buckwheat flour (1.12 $\pm 0.01 \mathrm{mg}$ GA/g d.b.). These results demonstrated that fermenting buckwheat sourdough with addition of lactic acid bacteria, L. plantarum or L.brevis, can have a positive influence and increase the content of easily extractable phenol compounds.

All crackers based on added buckwheat flour $(0.79 \pm 0.10 \mathrm{mg}$ GA/g d.b.) and sourdough $(0.94 \pm 0.07 \mathrm{mg} \mathrm{GA} / \mathrm{g}$ d.b. for W + BSD_LP, and $1.01 \pm 0.06 \mathrm{mg} \mathrm{GA} / \mathrm{g}$ d.b. for W + BSD_LB, respectively) had greater $\mathrm{TP}$ content in comparison to control sample (for W + BF) $(0.21 \pm 0.04 \mathrm{mg} \mathrm{GA} / \mathrm{g}$ d.b.). Even though all samples showed loss of TP during baking, the TP content of crackers with sourdough was 4.5 times greater as compared with to control sample. Comparing the TP content between crackers and dough it can be concluded that the control samples displayed the greatest TP losses (around $71 \%$ ).

Although Đordević et al. (2010) did not find considerable differences in FRAP values during spontaneous grain (wheat, buckwheat, rye) fermentation with L. rhamnosus, we measured anti-oxidative activities (FRAP values) in extracts of dough and crackers with added buckwheat and sourdough fermented with L. plantarum (LP) and L. brevis (LB) (Fig. 2.). Results have shown that the substitution of $20 \%$ of wheat flour with buckwheat flour and sourdough can have a positive influence on FRAP dough values. Extracts of sourdough samples (W + BSD_LP and W + BSD_LB) had significantly $(\mathrm{p}<0.05)$ greater FRAP values in relation to sample with buckwheat flour (V+BF) (Fig. 2.). The increase in anti-oxidative activity could be a consequence of changes that happen during sourdough fermentation. There is an increase in concentrations of easily soluble and extractable components that show ability of reduction $\mathrm{Fe}^{3+} / \mathrm{Fe}^{2+}$ due to activity of bacteria of lactic acid fermentation. The increase in antioxidative activity can be a consequence of releasing bonded phenol acids from cell walls or hydrolysis of rutin into quercetin, that shows greater anti-oxidative activity (Heim et al., 2002; Jiang et al., 2007). After baking, control crackers had the lowest FRAP value (7.76 mmol $\mathrm{Fe}^{3+} / \mathrm{g}$ d.b.). The greatest ability of reduction $\mathrm{Fe}^{3+} / \mathrm{Fe}^{2+}$ was manifested by crackers based on adding buckwheat sourdough (16.84 and $15.84 \mathrm{mmol} \mathrm{Fe}^{3+} / \mathrm{g}$ d.b.) in relation to buckwheat flour (10.42 mmol Fe $\mathrm{Fe}^{3+} / \mathrm{g}$ d.b.) addition. No significant difference $(p<0.05)$ was noted between FRAP values in crackers with sourdough.

The results of sensory evaluation of crackers are shown in the Table 3.

The sensory evaluation of representative properties of crackers show that crackers of satisfactory quality can be produced by adding buckwheat flour or sourdough fermented with starter cultures $L$. plantarum and L. brevis. No significant difference $(p<0.05)$ was observed in terms of odour and taste between the wheat and crackers with addition of buckwheat flour. Presented results were in agreement with those reported by Sedej et al. (2011) in which refined and wholegrain buckwheat flour was used to substitute wheat flour in crackers for-
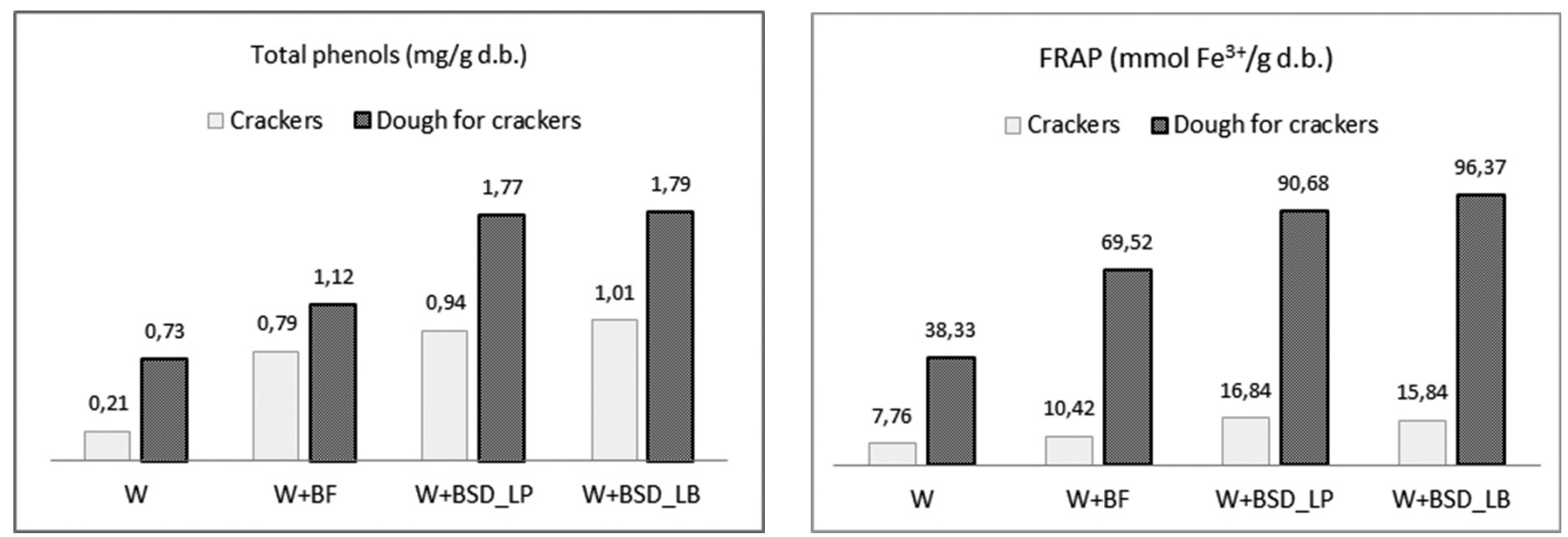

Fig. 2. Total phenols content and antioxidant activity (FRAP) of the dough for crackers and crackers (W - Wheat crackers; W + BF - Wheat crackers with buckwheat flour; W + BSD_LP - Wheat crackers with buckwheat sourdough fermented with L. plantarum (LP); W + BSD_LB - Wheat crackers with buckwheat sourdough fermented with L. brevis (LB)). 
Tab. 3. Sensory scores of crackers.

\begin{tabular}{lcccc}
\hline \multirow{2}{*}{ Property } & \multicolumn{3}{c}{ Crackers } \\
\cline { 2 - 5 } & $\mathrm{W}$ & $\mathrm{W}+\mathrm{BF}$ & $\mathrm{W}+$ BSD_LP & W + BSD_LB \\
\hline Appearance & $4.21 \pm 0.91^{\mathrm{a}}$ & $4.14 \pm 0.24^{\mathrm{a}}$ & $4.29 \pm 0.27^{\mathrm{a}}$ & $4.36 \pm 0.56^{\mathrm{a}}$ \\
Texture & $4.20 \pm 0.49^{\mathrm{b}}$ & $4.37 \pm 0.57^{\mathrm{ab}}$ & $4.71 \pm 0.73^{\mathrm{a}}$ & $4.89 \pm 0.23^{\mathrm{a}}$ \\
Chewiness & $3.71 \pm 0.27^{\mathrm{b}}$ & $4.29 \pm 0.49^{\mathrm{a}}$ & $4.43 \pm 0.45^{\mathrm{a}}$ & $4.43 \pm 0.19^{\mathrm{a}}$ \\
Odour & $2,87 \pm 0.16^{\mathrm{a}}$ & $2.91 \pm 0.15^{\mathrm{a}}$ & $2.96 \pm 0.11^{\mathrm{a}}$ & $2.96 \pm 0.11^{\mathrm{a}}$ \\
Taste & $4.29 \pm 0.41^{\mathrm{b}}$ & $4.46 \pm 0.47^{\mathrm{ab}}$ & $4.80 \pm 0.60^{\mathrm{a}}$ & $4.89 \pm 0.23^{\mathrm{a}}$ \\
\hline Weighted mean value & 3.86 & 4.03 & 4.24 & 4.31 \\
\hline
\end{tabular}

*Results are presented as the mean value \pm standard deviation (SD).

${ }^{* *}$ Values in the same row marked with different letters are statistically significantly different $(\mathrm{p}<0.05)$.

W - Wheat crackers; W + BF - Wheat crackers with buckwheat flour; W + BSD_LP - Wheat crackers with buckwheat sourdough fermented with $L$. plantarum (LP); W + BSD_LB - Wheat crackers with buckwheat sourdough fermented with $L$. brevis (LB).

mulation. Also, there was no significant difference $(\mathrm{p}<0.05)$ in terms of appearance and texture among wheat and crackers with addition buckwheat flour. This is in contrast to the results obtained by Sedej et al. (2011). In their research, authors used refined and wholegrain buckwheat flour (without wheat flour) for the production of crackers. In comparison to their study we used buckwheat flour as partial replacement for wheat flour $(20 \%$ wheat flour replaced with buckwheat flour). The results of sensory evaluation show that the addition of buckwheat flour in the formulation could improve chewiness of crackers compared to wheat crackers. Similar findings were reported in a study by Sedej et al. (2011). To the best of our knowledge, there is no published data on the effect of buckwheat sourdough, fermented with $L$. plantarum and $L$. brevis, on the properties of crackers. In our study, we used buckwheat sourdough to substitute $20 \%$ of wheat flour in the crackers formulation. Addition of buckwheat sourdough can improve texture, chewiness and taste of crackers compared to wheat crackers. There is a significant difference $(\mathrm{p}<0.05)$ in the terms of texture, chewiness and taste among crackers with buckwheat sourdough and wheat crackers, while there is no significant difference $(\mathrm{p}<0.05)$ for odour and appearance (see table 3$)$. As can be seen from the Table 3, the highest weighted mean value was obtained for the buckwheat sourdough crackers. According to qualitative category all crackers are graded as products of "very good quality" (weighted mean value from 3.5 to 4.5 ).

\section{Conclusion}

The influence of buckwheat sourdough on the functional and sensory properties of crackers was investigated in this study. It was shown that replacing $20 \%$ of wheat flour with the buckwheat flour and sourdough increased the total phenol content and anti-oxidative activity of cracker compared to wheat crackers. The results of sensory analysis show that the use of buckwheat sourdough as a partial substitute of wheat flour did not negatively contribute to sensory properties of crackers. In addition, the best quality was achieved in crackers with added buckwheat sourdough regardless of starter culture L. plantarum or L. brevis used. This clearly shows that buckwheat sourdough can become a useful ingredient in the cracker production.

\section{References}

Angioloni A, Romani S, Gaetano Pinnavaia G, Dalla Rosa M (2006) Eur. Food Res. Technol. 222: 54-57.

Armero E, Collar C (1996) J. Food Sci. 61: 299-303.

Banu I, Vasilean I, Aprodu I (2010) Food Sci. Technol. Res. 16: 571-576.

Benzie IF, Strain JJ (1996) Anal. Biochem. 239: 70-76.

Christa K, Soral-Smietana M (2008) Czech J. Food Sci. 26: 153-162.

Clarke CI, Farrell GM (2000) J. Sci. Food Agric. 80: 1237-1244.

Clarke CI, Schober TJ, Arendt EK (2002) Cereal Chem. 79: 640-647.

Di Cagno R, Rizzello CG, De Angelis M, Cassone A, Giuliani G, Benedusi A, Limitone A, Surico RF, Gobbetti M (2008) J. Food Prot. 71: 1491-1495.

Dietrych-Szostak D, Oleszek W (1999) J. Agric. Food Chem. 47: 4384-4387.

Đorđević TM, Šiler-MarinkovićSS, Dimitrijević-Branković SI (2010) Food Chem. 119: 957-963.

Hansen B, Hansen A (1994) Z. Lebensm. Unters. Forsch. 198: 202-209.

Heim KE, Tagliaferro AR, Bobilya DJ (2002) J. Nutr. Biochem. 13: 572-584.

Jiang P, Burczynski F, Campbell C, Pierce G, Austria JA, Briggs CJ (2007) Food Res. Int. 40: 356-364.

Katina K, Arendt EK, Liukkonen KH, Autio K, Flander L, Poutanen K (2005) Trends Food Sci. Technol. 16: 104-112. 
Katina K, Liukkonen KH, Norja AK, Adlercreutz H, Heinonen SM, Lampi AM, Pihlava JM, Poutanen K, (2007) J. Cereal Sci. 46: 348-355.

Kreft S, Knapp M, Kreft I (1999) J. Agric. Food Chem. 47: 4649-4652.

Kuchtová V, Karovičová J, Kohajdová Z, Minarovičová L (2016) Acta Chim Slov. 9: 54-57.

Liukkonen KH, Katina K, Wilhelmsson A, Myllymaki O, Lampi AM, Kariluoto S, Piironen V, Heinonen SM, Nurmi T, Adlercreutz H, Peltoketo A, Pihlava JM, Heitaniemi V, Poutanen K (2003) Proc. Nutr. Soc. 62: 117-122.

Meuser F, Zense TH (1993) Carbohydr. Polym. 21: 179-181.

Michalska A, Ceglinska A, Amarowicz R, Konrad Piskula M, Szawara-Nowak D, Zielinski H (2007) J. Agric. Food Chem. 55: 734-740.

Noor Aziah AA, Komathi CA (2009) Intern. Food Res. 16: 479-482.
Sanz Penella JM, Tamayo Ramos JA, Haros M (2012) Food Bioprocess Tech. 5: 2370-2380.

Schober TJ, Dockery P, Arendt EK (2003) Eur. Food Res. Technol. 217: 299-304.

Sedej I (2011) Faculty of Technology. University of Novi Sad, Serbia. Doctoral thesis.

Sedej I, Sakač M, Mandić A, Mišan A, Pestorić M, Šimurina O, Čanadanović-Brunet J (2011) Food Sci. Technol. 44: 694-699.

Selimović A, Miličević D, Jašić M, Selimović A, Ačkar Đ, Pešić T (2014) Croat. J. Food Sci. Technol. 6: 43-50.

Singleton VR, Orthifer R, Lamuela-Raventos RM (1999) Methods Enzymol. 299: 152-178.

Thiele C, Gänzle MG, Vogel RF (2002) Cereal Chem. 79: 45-51.

Wehrle K, Arendt EK (1998) Cereal Chem. 75: 882-886.

Wehrle K, Grau H, Arendt EK (1997) Cereal Chem. 74: $739-744$. 